\title{
Future probabilistic hot summer years for overheating risk assessments
}

\author{
C. Liu ${ }^{\text {a, }}{ }^{*}$, T. Kershaw ${ }^{\text {a }}$, M.E. Eames ${ }^{\text {b }}$, D.A. Coley ${ }^{\text {a }}$ \\ ${ }^{a}$ Dept. Architecture and Civil Engineering, University of Bath, Claverton Down Road, Bath, BA2 7AY, UK \\ ${ }^{\mathrm{b}}$ College of Engineering, Mathematics and Physical Sciences, University of Exeter, Prince of Wales Road, Exeter, EX4 4PL, UK
}

\section{A R T I C L E I N F O}

\section{Article history:}

Received 13 April 2016

Received in revised form

19 May 2016

Accepted 20 May 2016

Available online 24 May 2016

\section{Keywords:}

Climate change

Overheating risk

Thermal comfort

Probabilistic future hot summer year

Weighted cooling degree hours

Physiologically equivalent temperature

\begin{abstract}
A B S T R A C T
As the 2003 Paris heatwave showed, elevated temperatures in buildings can cause thousands of deaths. This makes the assessment of overheating risk a critical exercise. Unfortunately current methods of creating example weather time series for the assessment of overheating are based on a single weather variable, and hence on only one driver of discomfort or mortality. In this study, two alternative approaches for the development of current and future weather files are presented: one (pHSY-1) is based on Weighted Cooling Degree Hours (WCDH), the other (pHSY-2) is based on Physiologically Equivalent Temperature (PET). pHSY-1 and pHSY-2 files were produced for fourteen locations. These were then compared with the existing probabilistic future Design Summer Year (pDSY) and the probabilistic future Test Reference Year. It was found that both pHSY-1 and pHSY-2 are more robust than the pDSY. It is suggested that pHSY-1 could be used for assessing the severity and occurrence of overheating, while pHSY-2 could be used for evaluating thermal discomfort or heat stress. The results also highlight an important limitation in using different metrics to compare overheating years. If the weather year is created by a ranking of a single environmental variable, to ensure consistent results assessment of the building should be with a similar single metric (e.g. hours $>28^{\circ} \mathrm{C}$ or WCDH), if however the weather year is based upon several environmental variables then a composite metric (e.g. PET or Fanger's PMV) should be used. This has important implications for the suitability of weather files for thermal comfort analysis.

๑ 2016 The Authors. Published by Elsevier Ltd. This is an open access article under the CC BY-NC-ND license (http://creativecommons.org/licenses/by-nc-nd/4.0/).
\end{abstract}

\section{Introduction}

Two central functions of buildings are to provide shelter from the external environment and to ensure thermal comfort for the occupants. Given the lifetime of buildings, shelter and comfort need to be ensured over a considerable time frame. Under the RCP8.5 greenhouse gas emissions scenario, projections of global mean surface temperatures show an increase of between $2.6^{\circ} \mathrm{C}$ and $4.8^{\circ} \mathrm{C}$ by the end of this century, relative to a 1986 to 2005 baseline [1]. The estimation of temperature increase is highly dependent upon the emission scenarios. According to the 2015 Paris Climate Conference, the increase of global temperature might be limited to $1.5{ }^{\circ} \mathrm{C}$ (relative to pre-industrial level) by 2020s due to the international efforts in reducing greenhouse gas emission [2]. Research predicts a significant increase in overheating risk under a changing climate with different emission scenarios [3-8]. People with

\footnotetext{
* Corresponding author.

E-mail address: C.Liu2@bath.ac.uk (C. Liu).
}

cardiovascular and heart-disease are more vulnerable $[9,10]$ and would be under higher risk of heat-related illness due to global warming. Therefore acceptable internal conditions within buildings need to be demonstrated under a climate that will change considerably, and industry and academia supported in doing so with the provision of suitable weather time series.

The Chartered Institution of Building Service Engineers (CIBSE) provides Design Summer Years (DSY) for assessing overheating risk for fourteen sites across the UK (see Fig. 1). The CIBSE DSY is a continuous year picked from around 21 years (typically 1983-2004) of observed weather data based on a simple selection method [11]. The 21 years of weather data are ranked in ascending order according to the mean summer (April-September) dry bulb temperature. The DSY is the year ranked at the middle of upper quartile (typically the third warmest). This methodology however, has several issues. For instance, among the 21 years, years with significant amounts of missing data were discarded so that the number of complete years available for each site varied from 6 (Southampton and Swindon) to 21 (Edinburgh and Glasgow). Thus DSYs exist for sites with a small number of complete years which 


\section{Nomenclature}

WCDH Weighted Cooling Degree Hours

PET Physiologically Equivalent Temperature $\left({ }^{\circ} \mathrm{C}\right)$

PMV Predicted Mean Vote

TRY Test Reference Year

DSY Design Summer Year

pTRY Future probabilistic Test Reference Year

pDSY Future probabilistic Design Summer Year

HSY Hot Summer Year

pHSY-1 Future probabilistic Hot Summer Year created based on WCDH

pHSY-2 Future probabilistic Hot Summer Year created based on PET

abrT air temperature $\left({ }^{\circ} \mathrm{C}\right)$

Tcomf adaptive comfort temperature $\left({ }^{\circ} \mathrm{C}\right)$

Trm running mean outdoor temperature $\left({ }^{\circ} \mathrm{C}\right)$

Top operative temperature $\left({ }^{\circ} \mathrm{C}\right)$

$\sigma \quad$ standard deviation

$\Delta \quad$ absolute difference

$\%$ relative difference

$\mathrm{R}^{2} \quad$ coefficient of determination

hence might not be particularly warm compared to the long-term mean [12]. CIBSE also provides Test Reference Years (TRY), which are used for predicting the energy consumption of buildings. Unlike the DSY, the TRY is designed to be a typical year. The CIBSE TRY is a composite year which consists of the 12 most representative months, chosen from the 21 years of historical weather data. The most representative January, February and so on are individually selected using Finkelstein-Schafer (FS) statistics based upon air temperature, solar radiation and wind speed [11]. Unfortunately it is known that, when applied to a building, the CIBSE TRY can predict greater overheating risk than the CIBSE DSY for some sites e.g. Norwich and Newcastle [12], this is the reverse of what might be expected. It was found that updating the baseline data to a more recent period with better data could not solve this issue [13]. For instance, the updated DSY remained the same as the original DSY for Norwich and Newcastle.

There have been alternatives to the CIBSE DSY approach suggested for overheating studies. Jentsch et al. [13] proposed a nearextreme summer reference year (SRY) which is a composite year where the current TRY selection process was adjusted to a candidate year with many degree hours $>18{ }^{\circ} \mathrm{C}$ and another candidate year with high direct solar radiation to generate one SRY that includes extreme temperatures and high solar radiation. The resultant SRY [13] consistently indicated more severe overheating risk than the TRY at the fourteen sites when used in a simulation of a non-realistic building [14]. Instead of a single DSY, Eames [15] presented three probabilistic DSYs for one location to investigate a range of potential overheating risks. These new DSYs were selected from updated baseline weather data (1983-2013) based on the analysis of actual warmest events and their return periods. The three probabilistic DSYs were defined as a moderate warm event year, an intense extreme year and a long extreme year, respectively. A generalised extreme value [16] was used for estimating return periods of the hot event year. Weighted cooling degree hours (WCDH), combined with two alternative overheating metrics were used to determine the warmest events. The alternative overheating metrics are the static weighted cooling degree hours (SWCDH) and the threshold weighted cooling degree hours
(TWCDH). SWCDH took account of regional threshold temperatures related to excess summer mortality, while TWCDH combined the adaptive comfort temperature with the regional threshold temperature. Though there have been different approaches to the current summer reference years to be used for dynamic thermal simulations in other countries [17,18], mean dry bulb temperature is normally used to measure the warmth of summer. In addition to the CIBSE TRY/DSYs which are intended to be representative of the current climate, future TRY/DSYs have been created in the UK. CIBSE incorporated the UK Climate Impacts Programme (UKCIP02) climate change scenarios via a mathematical transformation (termed morphing) into the current TRYs and DSYs to create the future CISBE TRYs and DSYs. Since the future CIBSE TRY/DSYs are based upon a mathematical transformation of the historic files, the issues mentioned above still exist in the future CIBSE DSYs. Thus the improvement of future DSYs has become an important issue.

The morphing approach uses averaged historical observations of weather as a baseline and climate change projections from a climate model [19]. The morphing algorithms apply the monthly climate change projections to the baseline historical data depending on the weather variable to create the future weather data. For example, the Climate Change Weather File Generator [20] developed by the University of Southampton uses this method to combine CIBSE TRYs and DSYs with UKCIP02 climate change projections to create future weather files for the UK. The main limitation with this method is that it is reliant upon observed weather data spanning many years (in order to form the baseline TRYs and DSYs), which is unavailable for many locations. The other method is based on the UKCP09 weather generator [21], which can produce daily and hourly synthetic weather data for both a control period (1961-1990) and future time periods (from 2020s to 2080s) at a $5 \mathrm{~km}$ by $5 \mathrm{~km}$ grid resolution. The UKCP09 weather generator has allowed researchers to create time series of current and future weather without having to rely upon historical observations, and this has led to several novel approaches [22-24] for the creation of future DSYs.

The DSY was intended to represent a warm but non-extreme year, which could be used to assess summertime overheating. However, it is known that the temperature inside a building is dependent on more than just the external temperature, including wind speed, solar radiation and relative humidity. It has been shown that although the DSY is ranked the 3rd warmest externally amongst the 21 or so years of weather observations, its ranking falls when considering internal temperatures and thermal discomfort [25]. The method for the creation of the DSY selects a warm year, but this may be as a result of a warmer than typical spring, rather than a hotter than normal summer, or the existence of any heat wave. (When considering morbidity or mortality from thermal stress it is uncharacteristically high temperatures sustained over several days, humidity and wind speed that are important.) Kershaw et al. [25] compared TRYs and DSYs to the baseline datasets used to create them; they found that years such as 2003, which resulted in so-many deaths across the UK and Europe, are not necessarily ranked highly by the DSY selection procedure. For instance 2003 is ranked 14th out of 19 in terms of mean summertime external temperature in Plymouth. Indeed, the DSY selection process consistently underestimates the potential amount and severity of overheating and thermal discomfort within the buildings.

There is therefore a need to create new reference years that can provide additional information about overheating risk in buildings and the risk to human health. In this paper we describe the creation of two new reference years termed 'hot summer years'. One based upon weighted cooling degree hours, which will highlight years with high temperatures and another based upon the 


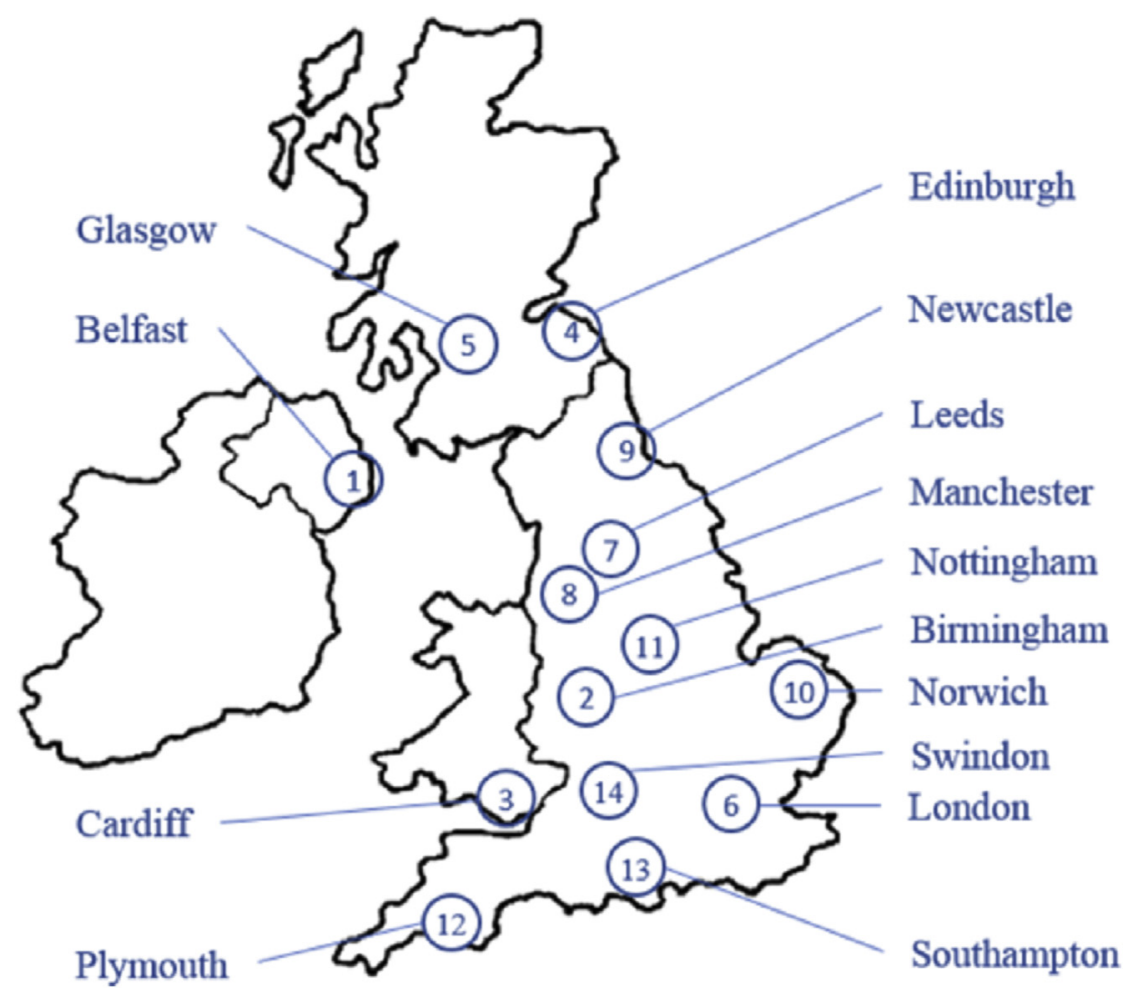

Fig. 1. Map of the UK showing the fourteen sites used by CIBSE for the DSY and TRY.

physiologically equivalent temperature, which is dependent upon both air and radiant temperatures, humidity and wind speed. It is hoped that these new reference years will enable practitioners to examine the risk of overheating and thermal discomfort within their building designs in a more holistic manner.

\section{UKCP09 weather generator}

UKCP09 weather generator [21] is based on a stochastic rainfall model taking the daily precipitation as the primary variable, calculating other weather variables according to the inter-variable relationships with rainfall. Each run of the weather generator yields 100 sets of 30-year long synthetic weather data, comprising 100 estimates of future climate change each augmented with 30years of weather data (climate is typically defined over a 30 -year period). The generated future synthetic weather data incorporates the UK Climate Projections (UKCP09). Unlike the deterministic climate projections from UKCIP02, UKCP09 provides a range of possible climate change projections based on a probability density function (PDF) formed from many iterations of regional and global climate models. The probabilistic nature of the UKCP09 climate change projections allows them to be used for risk-based decision making. The UKCP09 weather generator can produce future weather data under three emission scenarios such as low, medium and high emission scenarios which correspond to the SRES B1, SRES A1B and SRES A1FI presented by the IPCC Special Report on Emission Scenarios (SRES) [26]. The UKCP09 weather generator offers nine daily and seven hourly weather variables as shown in Table 1. Other weather variables such as wind speed and direction, ground temperature, dew point temperature, atmospheric pressure, cloud cover, etc. that are required for building simulation need to be calculated from these as they are not included directly in the data. The methods for calculating these missing weather variables can be found in Eames et al. [23] and Watkins et al. [27].

\section{Methodology}

In order to distinguish the new summer years from the existing probabilistic future DSYs (pDSY), the new summer years are referred to as probabilistic Hot Summer Years (pHSYs). In the following the two methods are presented and compared with the methods used for the future probabilistic TRY (pTRY) and pDSY. The probabilistic Hot Summer Year No.1 (pHSY-1) is based upon assessment of weighted cooling degree hours (WCDH), the probabilistic Hot Summer Year No.2 (pHSY-2) is based upon assessment of the physiologically equivalent temperature (PET). All four weather years were created using the same future weather data for 2050s under the high emission scenario (SRES A1FI) and produced by the UKCP09 weather generator, however the method is a general one, and other emission scenarios or time periods could be used. Three percentiles (10th, 50th, and 90th) were created for pDSY, pHSY-1, pHSY-2 and pTRY type files for the same fourteen UK sites (see Fig. 1) that current CIBSE DSYs and CIBSE TRYs are normally offered. Once these files were created, the risk of overheating and thermal discomfort was investigated using a reference conceptual building outlined in CIBSE TM 49 [28]. The reference conceptual building is a free running building in which the internal operative temperature is assumed to be the same as the external dry bulb temperature. According to CIBSE TM 49 [28], this reference model is appropriate for representing naturally ventilated buildings, such as domestic houses, and was introduced as part of the development of a new summer reference year for overheating risk assessment.

\subsection{Two approaches for future probabilistic hot summer years}

The pHSY-1 is based on WCDH $[28,29]$ during the summer (June, July and August), while the pHSY-2 is based on the hours of PET $>23^{\circ} \mathrm{C}$, which is defined as warm and slight heat stress, this value is equivalent to a predicted mean vote (PMV) of $>0.5$ above which the 
Table 1

UKCP09 weather generator outputs.

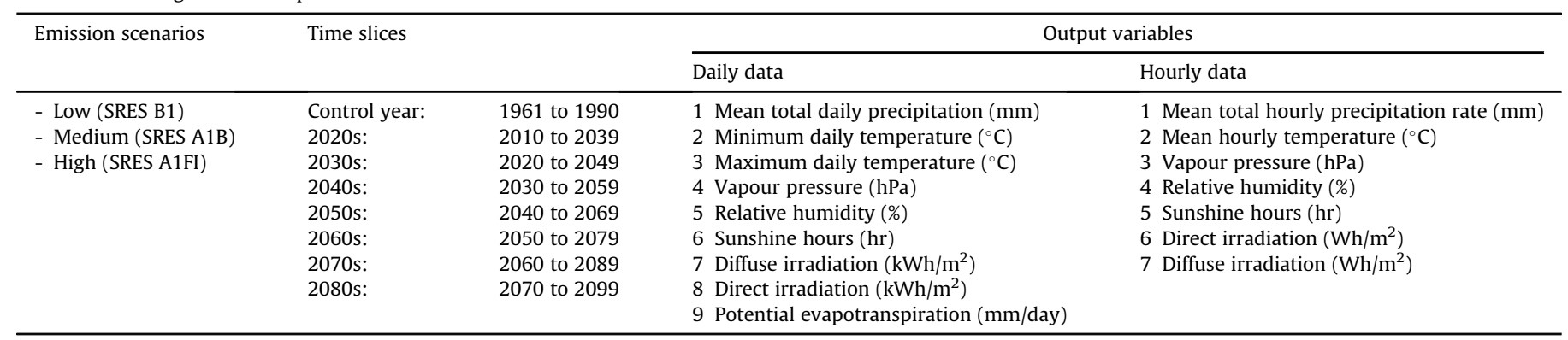

space is considered as not providing thermal comfort [30].

The WCDH is given by:

$T_{\text {comf }}=0.33 T_{r m}+18.8$

And

$W C D H=\sum_{\text {all hours }}\left(T_{o p}-T_{\text {comf }}\right)^{2}, T_{o p}-T_{\text {comf }}>0$

where $T_{\text {comf }}$ is the comfort temperature $\left({ }^{\circ} \mathrm{C}\right)$ predicted from the adaptive comfort model given in BS EN15251 [31], $T_{r m}$ is the running mean outdoor temperature $\left({ }^{\circ} \mathrm{C}\right)$, and $T_{o p}$ is the indoor operative temperature $\left({ }^{\circ} \mathrm{C}\right)$. The use of a quadratic difference between $T_{o p}$ and $T_{\text {comf }}$ increases the emphasis on the discomfort temperature. Smith and Hanby [22] presented different methods for creating future design summer years and used WCDH to measure the warmth of their years. It was found that the differences between the methods were enlarged due to the higher impact on the larger differences between $T_{o p}$ and $T_{\text {comf }}$. CIBSE TM49 [28] also suggested the use of WCDH to measure the warmth of 32 years of observed weather data (1975-2006) and selected the years with the hottest summer and a moderately warm summer i.e. 1976 and 1989 for London. Year 2003 was also selected as it showed a high WCDH during a short hot spell, namely the August 2003 heatwave.

As thermal comfort is affected by not only temperature but also other thermally related weather variables, PET was used for creating pHSY-2. PET was developed by Mayer and Höppe [32] and has been recommended in German building guidelines [33] as one of the main thermal indices. It considers all the thermally related weather variables such as air temperature, solar radiation, relative humidity and wind speed. Based on the Munich Energy-balance Model for Individuals (MEMI) [34,35], outdoor air temperature is converted into an equivalent temperature in a typical standardised indoor environment where it is assumed that the air temperature is equivalent to the mean radiant temperature, air speed is equal to $0.1 \mathrm{~m} / \mathrm{s}$ and water vapour pressure is $12 \mathrm{hPa}$. Real comfort values for skin temperature and sweat rate are dependent on activity as well as climate, however, in line with the empirical data, the expected comfort values were used in Fanger's PMV calculation. Unlike Fanger's PMV approach, in which these comfort values were only dependent on activity, MEMI quantifies real skin temperature and sweat rate for activity and a given climate [35].

For the work reported here, the bioclimatic model RayMan Pro produced by the Meteorological Institute of the University of Freiburg was used to calculate PET, as it contains the MEMI model and has been used in urban climate studies [36-38]. Fig. 2 shows the procedure of generating pHSY-1 and pHSY-2. One hundred sets of 30-year complete weather files are constructed by combining outputs from the UKCP09 weather generator with missing weather variables such as wind speed and direction, generated as described above. Each set represents a single sampling of the UKCP09 climate change probability density function for the site. Hence the 100 sets cover predictions of little climate change to aggressive change. For each set of 30 years, the year with the highest WCDH is chosen as one HSY-1. In total, 100 HSY- 1 are derived from the 100 sets. These 100 HSY-1 are distinct, since they inherit 100 probabilistic climate projections from UKCP09. These 100 HSY-1 are then sorted in ascending order of WCDH to produce pHSY-1. The pHSY-2 are created in the same way but using hours of PET $>23^{\circ} \mathrm{C}$, rather than WCDH.

In addition, future pTRYs and pDSYs were produced in order to compare the pHSY-1 and pHSY-2 with them. For the purpose of maintaining the original methods used for the creation of the CIBSE TRY and DSY, the method suggested by Eames et al. [23] was used for creating the future pTRYs, while the method for creating future pDSYs was that suggested by Ref. [22]. That is, the FS function used in CIBSE TRY and the simple selection method used in the CIBSE DSY [11]. These were applied to the 100 sets of 30-year time series of weather data to produce 100 TRYs and 100 DSYs respectively. From these 100 candidate years, pTRYs and pDSYs were produced based on sorting the years into ascending order of mean summer temperature. (pTRY is a composite year while pDSY is a continuous year, as in CIBSE TRY and DSY.) The comparison between the methods used for the pHSY-1, pHSY-2, pDSY and pTRY are described in Table 2.

\subsection{Assessment methods}

Typical years such as the pTRY are used for assessing the energy performance of buildings while the concept of summer years such as the pDSY, pHSY-1 and pHSY-2 are used for assessing risk of overheating and thermal discomfort. The method used for the original CIBSE DSY is not robust, in that, it can indicate less overheating than the CIBSE TRY for some UK sites such as Newcastle, Norwich and Nottingham [12]. Kershaw et al. [25] also found that the DSY is likely to underestimate the overheating risk due to its simple selection method. The robustness of the pHSY- 1 and pHSY-2 were examined by comparison with the pTRY and pDSY for the fourteen UK sites. Four assessment metrics were used as follows:

(1) WCDH (same as the warmth measurement used for pHSY-1 creation)

(2) Hours of temperature $>28^{\circ} \mathrm{C}$ (a common measure of overheating in building regulations)

(3) Hours of PET $>23^{\circ} \mathrm{C}$ ( same as the warmth measurement used for pHSY-2 creation)

(4) Hours of PMV $>0.5$ (a common measure of thermal comfort in building regulations)

Assessment metric (2) refers to CIBSE Guide A [39] while (4) 


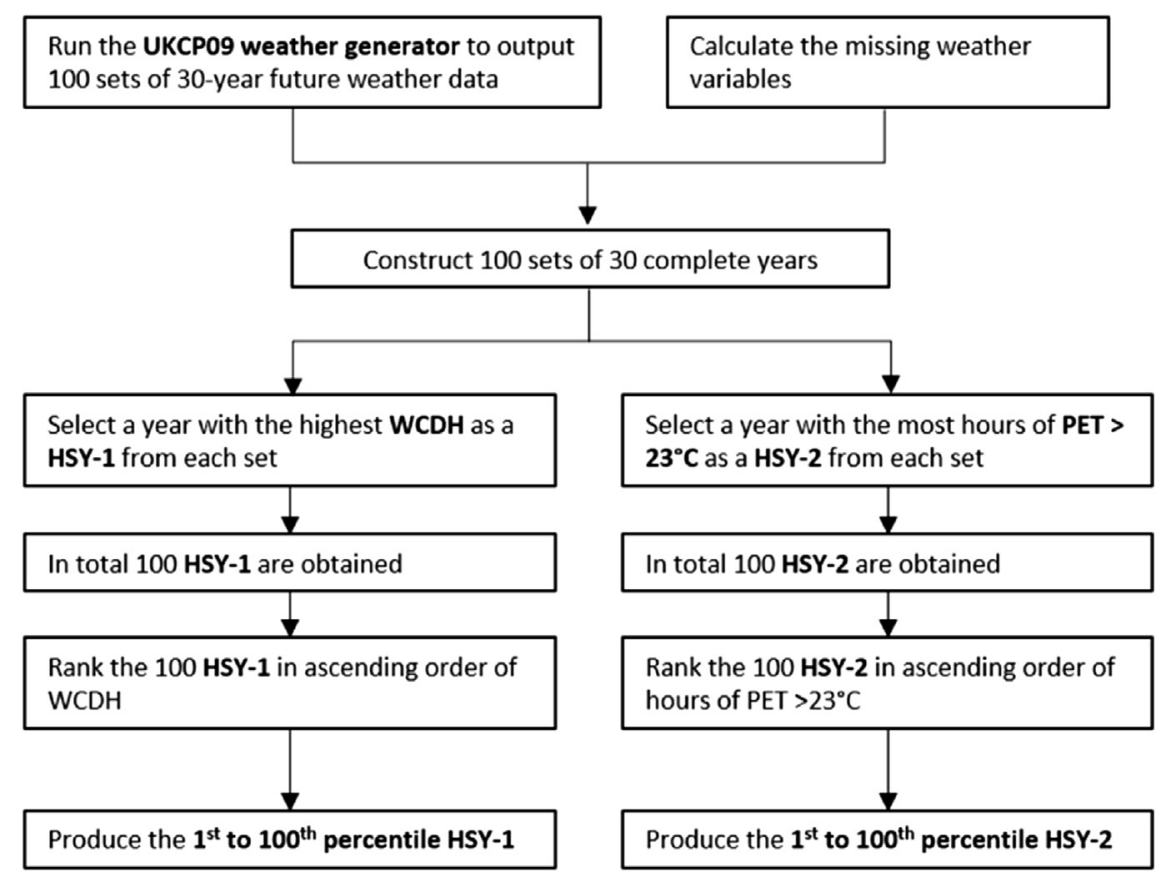

Fig. 2. Procedure for creating pHSY-1 and pHSY-2.

refers to ANSI/ASHRAE Standard 55-2013 [40].

\section{Results and discussion}

In the following the pTRY and three probabilistic summer years (pDSY, pHSY-1 and pHSY-2) are compared in terms of overheating and thermal discomfort in a reference conceptual building. The pTRY, pDSY, pHSY-1 and pHSY-2 were compared for all fourteen sites to find out whether pHSY-1 gave greater overheating and if pHSY-2 showed more thermal discomfort hours than the pTRY at all sites (see Section 4.1). In addition, low to high percentiles (e.g. 10th, 50th and 90th) of HSY-1 and HSY-2 were investigated to find out whether the overheating risk or thermal discomfort became more severe when a higher percentile was chosen (see Section 4.2). If so, building practitioners would be able to choose the percentile which best represents the client's view of climate change, and the risk to occupants. For example, when designing a care home it might be best to design for a more aggressive (higher percentile) prediction of climate change than when designing a school. This is because the school can be closed and pupils not required to attend; whereas this is not possible with a care home. As stated before, each run of the UKCP09 weather generator produces 3000 synthetic future weather files to be used in pHSY-1 and pHSY-2 creation. However, each run of UKCP09 weather generator will produce different datasets due to the random sampling method employed by the UKCP09 weather generator. Therefore, different users will be offered different datasets unless the same seed number for running the UKCP09 weather generator is used. As a check of whether this might change the amount of overheating, the impact on pHSY-1 and pHSY-2 of using different seeds is presented in Section 4.3. The recommendation to the building practitioners on selecting probabilistic weather files is stated in Section 4.4.

\subsection{Investigation of the robustness of probabilistic hot summer years}

Fig. 4 shows the overheating risk in the reference conceptual building caused by the $90^{\text {th }}$ percentile TRY, DSY, HSY-1 and HSY-2 using assessment metrics (1) and (2), while thermal discomfort based on assessment metrics (3) and (4) is presented in Fig. 5.

Fig. 4 shows that WCDH calculated from the $90^{\text {th }}$ percentile HSY1 is constantly higher than that from the $90^{\text {th }}$ percentile TRY in all of the fourteen sites, though the difference varies between the sites. As shown in Table 3, the absolute difference ranges from 924 (in Edinburgh) to 6457 (in Southampton) and the relative difference from $41 \%$ (in Nottingham) to 345\% (in Belfast). On average, over the 14 sites the difference is 2707 or $186 \%$. The $90^{\text {th }}$ percentile DSY and $90^{\text {th }}$ percentile HSY-2 show less overheating risk than the $90^{\text {th }}$

Table 2

Comparison of the methods for creating pTRY, pDSY, pHSY-1 and pHSY-2.

\begin{tabular}{|c|c|c|c|c|}
\hline & \multirow{2}{*}{$\begin{array}{l}\text { Typical year } \\
\text { (Composite) } \\
\text { pTRY }\end{array}$} & \multicolumn{3}{|c|}{$\begin{array}{l}\text { Summer years } \\
\text { (Continuous) }\end{array}$} \\
\hline & & pDSY & pHSY-1 & pHSY-2 \\
\hline Methods & $\begin{array}{l}\text { CIBSE TRY method } \\
\text { Finkelstein-Schafer statistics } \\
\text { functions }\end{array}$ & $\begin{array}{l}\text { CIBSE DSY method } \\
\text { The third hottest mean summer temperature } \\
\text { (April to September) }\end{array}$ & $\begin{array}{l}\text { WCDH during summer (June } \\
\text { to August) }\end{array}$ & $\begin{array}{l}\text { Hours of PET }>23^{\circ} \mathrm{C} \text { during summer } \\
\text { (June to August) }\end{array}$ \\
\hline $\begin{array}{l}\text { Ranking } \\
\text { method }\end{array}$ & $\begin{array}{l}\text { Ascending order of mean summer } \\
\text { temperature }\end{array}$ & Ascending order of mean summer temperature & Ascending order of WCDH & $\begin{array}{l}\text { Ascending order of the hours of PET } \\
>23^{\circ} \mathrm{C}\end{array}$ \\
\hline Usages & Energy performance assessment & \multicolumn{3}{|c|}{$\begin{array}{l}\text { Potential overheating risk and thermal discomfort assessment in free running buildings (i.e. non-air conditioned } \\
\text { buildings) }\end{array}$} \\
\hline
\end{tabular}


percentile TRY for 8 of 14 sites and 9 of 14 sites respectively. The number of hours $>28^{\circ} \mathrm{C}$ caused by the $90^{\text {th }}$ percentile HSY- 1 is also greater than the $90^{\text {th }}$ percentile TRY in all the UK sites except Nottingham. The absolute and relative difference ranges from -43 (in Nottingham) to 208 (in Southampton) and from -22\% (in Nottingham) to $544 \%$ (in Newcastle) respectively. In Nottingham however, the $90^{\text {th }}$ percentile HSY- 1 shows fewer hours $>28^{\circ} \mathrm{C}$ than that of the $90^{\text {th }}$ percentile TRY, but shows an increased number of hours at higher temperature $\left(>30^{\circ} \mathrm{C}\right)$ as shown in Fig. 3. The $90^{\text {th }}$ percentile DSY and the $90^{\text {th }}$ percentile HSY-2 show less overheating risk than the $90^{\text {th }}$ percentile TRY for 6 of 14 sites and 9 of 14 sites respectively. The pHSY-1 was chosen based upon WCDH, which put greater emphasis on the difference between air temperature and the adaptive comfort temperature. Thus, it is likely to include more hours of high summer temperatures than the pTRY and pDSY. The pHSY-1 can be considered more robust than the pDSY when using assessment metrics (1) and (2). The CIBSE DSY selection method misses some hotter years as it is defined as the third hottest weather year. The pHSY-2 was chosen based upon PET, which considers the combined effects of all the thermally related weather variables rather than just temperature. Therefore, the $90^{\text {th }}$ percentile HSY-2 may show reduced overheating risk than the $90^{\text {th }}$ percentile TRY for some sites when using the assessment metrics (1) and (2), which are based solely on air temperature.

We can see from Fig. 5 that the $90^{\text {th }}$ percentile HSY-2 shows the greatest number of hours of PET $>23{ }^{\circ} \mathrm{C}$ for the fourteen UK sites. Meanwhile, the hours of PMV $>0.5$ are always greater for the $90^{\text {th }}$ percentile HSY-2 than the $90^{\text {th }}$ percentile TRY. PET and PMV are both thermal indices that estimate the level of human thermal comfort and it has been shown that there is a linear relationship between them [41]. The HSY-2 was chosen based upon PET $>23^{\circ} \mathrm{C}$, which is equivalent to a PMV $>0.5$, the level above which people might feel discomfort and suffer slight heat stress [30]. Hence, using assessment metrics (3) and (4) should show similar results for HSY-2 for the fourteen sites. Mean values are $522(\sigma=111)$ and $531(\sigma=135)$ for hours of PET $>23^{\circ} \mathrm{C}$ and PMV $>0.5$ respectively across the fourteen sites. Table 4 shows hours of PET $>23{ }^{\circ} \mathrm{C}$ and PMV $>0.5$ produced by the $90^{\text {th }}$ percentile HSY- 2 range from 76 (in Belfast) to 374 (in Plymouth) and from 42 (in Leeds) to 258 (in Plymouth) respectively. In contrast, the $90^{\text {th }}$ percentile HSY- 1 and DSY show fewer discomfort hours than the $90^{\text {th }}$ percentile TRY for $\sim 50 \%$ of the UK sites, for assessment metrics (3) and (4). The methods used for pHSY-1 and pDSY ignore other thermally related

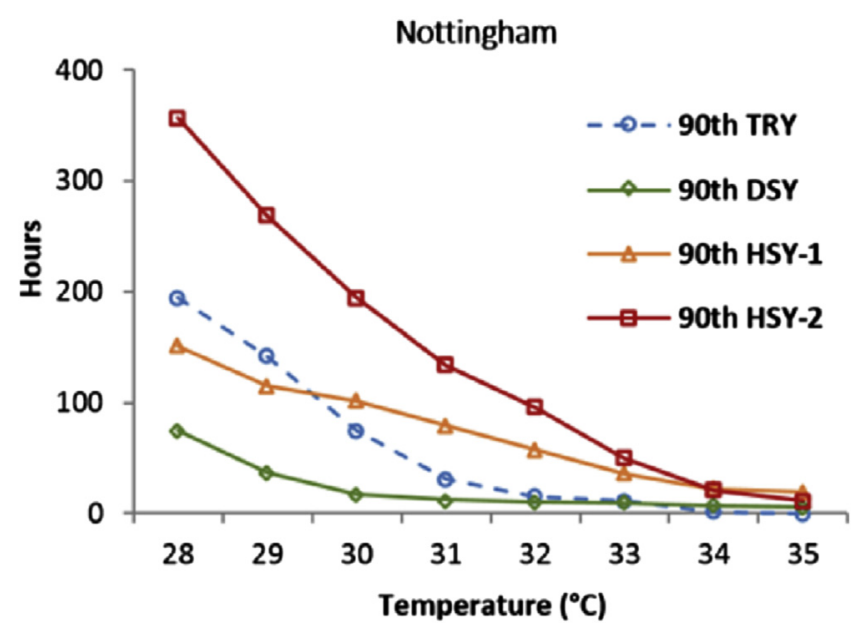

Fig. 3. Hours of temperature above high temperatures caused by the $90^{\text {th }}$ percentile TRY, DSY, HSY-1 and HSY-2 in Nottingham. weather variables that affect PET and PMV. For example, high air temperature with high wind speed and low relative humidity ratio might give a lower value of PET and PMV.

\subsection{Relative performance of low to high percentile hot summer years}

It would be ideal to be able to use probabilistic future summer years to examine future overheating risk for a given location and design to allow risk-based decision-making. Three cumulative distribution function probability levels, i.e. 10th, 50th and 90th percentiles were investigated for the PHSY-1 and pHSY-2 based on the four assessment metrics to see whether the overheating risk or the thermal discomfort is more severe when the higher percentile is selected, i.e. that they follow a logical order.

Fig. 6 presents overheating risk caused by 10th, 50th and 90th percentile HSY-1 based on assessment metrics (1) and (2) respectively. For all fourteen sites, the 10th percentile shows the least overheating and the 90th percentile the most overheating, suggesting that WCDH increases with the increase of percentile, as one would hope. The $50^{\text {th }}$ percentile lies between the 10 th and 90 th percentiles and provides information about the shape of the distribution. Similarly, hours $>28{ }^{\circ} \mathrm{C}$ in high percentile HSY-1 are greater than in low percentile HSY-1. According to the comparison, there is a close linear relationship $\left(R^{2}=0.92\right)$ between WCDH and hours $>28{ }^{\circ} \mathrm{C}$ caused by pHSY-1. Fig. 7 presents the results from 10th, 50th and 90th percentile HSY-2 based on assessment metrics (1) and (2). The $90^{\text {th }}$ percentile HSY-2 shows less overheating risk than 50th percentile HSY-2 in Cardiff, Manchester and Plymouth. In addition, the 10th percentile HSY-2 shows higher overheating risk than 50th percentile HSY-2 in London, Nottingham and Southampton. Hence, pHSY-2 is not suitable for risk-based decision making since overheating risk does not increase with the increasing percentile when using assessment metric (1) and (2).

Fig. 8 illustrates discomfort hours caused by 10 th, 50 th and 90 th percentile HSY-1 based on assessment metric (3) and (4) respectively. It cannot ensure that hours of PET $>23^{\circ} \mathrm{C}$ and PMV $>0.5$ from pHSY-1 increase with increasing percentile. For instance, 50th percentile HSY-1 shows the lowest number of hours of PET $>23^{\circ} \mathrm{C}$ in 5 of 14 sites. Meanwhile, 10th percentile HSY-1 shows more hours of PET $>23{ }^{\circ} \mathrm{C}$ than 50th percentile HSY-1 in 7 of 14 sites and, furthermore, most hours in two sites i.e. Birmingham and Plymouth. Similarly, the number of hours of PMV $>0.5$ caused by pHSY-1 is not higher with increasing percentile in 4 sites i.e. Belfast, Cardiff, Leeds and Plymouth. Fig. 9 presents discomfort hours caused by 10 th, 50th and 90th percentile HSY-2 based on assessment metrics (3) and (4) respectively. As expected, hours of PET $>23{ }^{\circ} \mathrm{C}$, are greater in the high percentile than in the low percentile HSY-2 as they were ranked based on the ascending order of hours of PET $>23^{\circ} \mathrm{C}$. Due to the close relationship between PET and PMV, pHSY-2 also shows more hours of PMV $>0.5$ with the increasing percentile. There is also a close linear relationship $\left(R^{2}=0.88\right)$ between the hours of PET $>23{ }^{\circ} \mathrm{C}$ and PMV $>0.5$ over the fourteen UK sites.

\subsection{The impact of random sampling within the weather generator}

Running the UKCP09 weather generator once has the potential to produce 3000 synthetic future weather years for one location. However, each iteration of the UKCP09 weather generator does not provide exactly the same future weather data for the same location due to the random sampling method employed when generating weather data. In order to see if this was a concern, we created two different future weather datasets for Norwich in 2050s under the high emission scenario to examine the impact of random sampling 

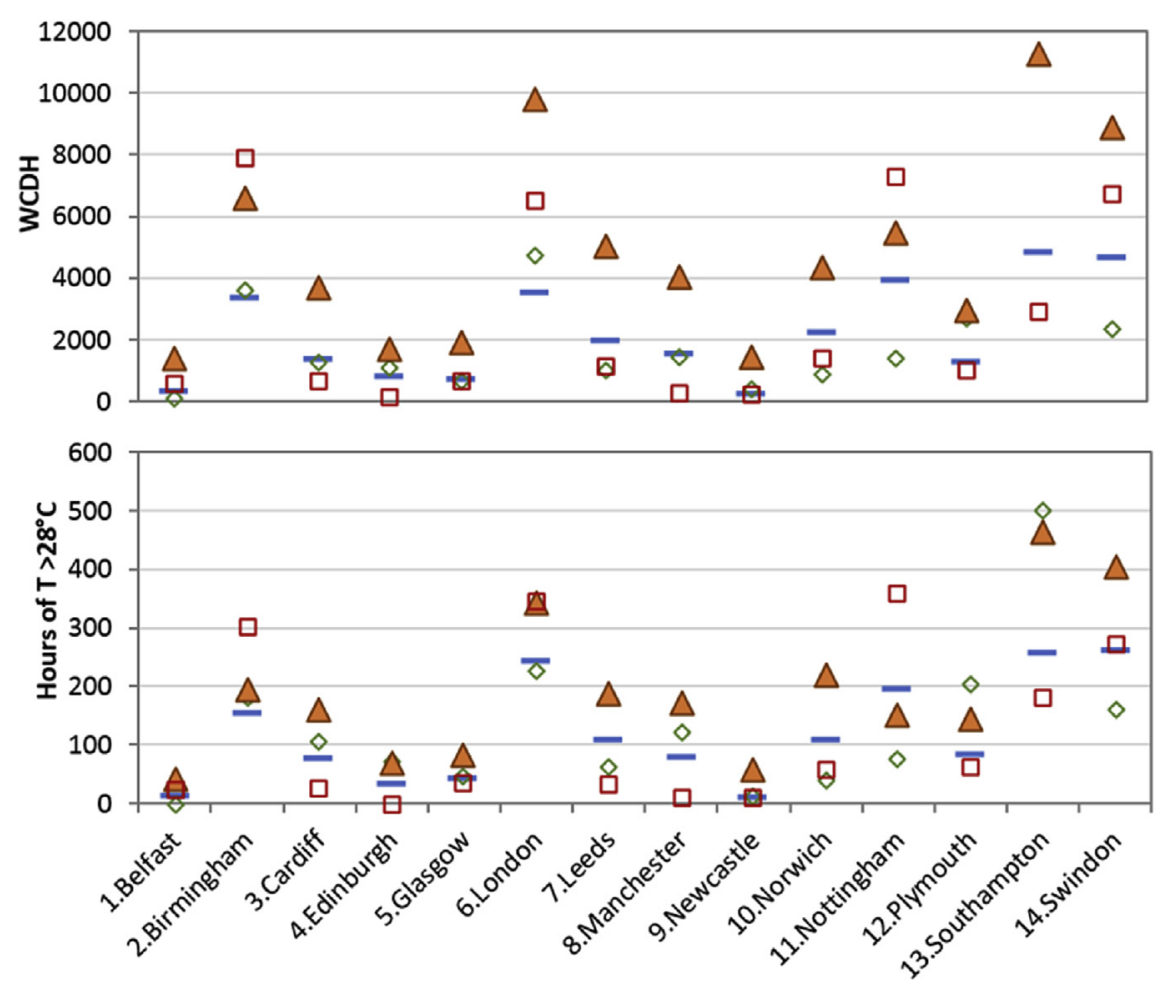

- 90th TRY $\diamond$ 90th DSY $\quad \Delta$ 90th HSY-1 $\quad$ 90th HSY-2

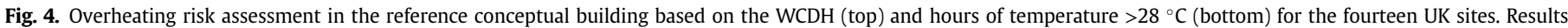
shown are the $90^{\text {th }}$ percentile TRY, DSY, HSY- 1 and HSY-2.
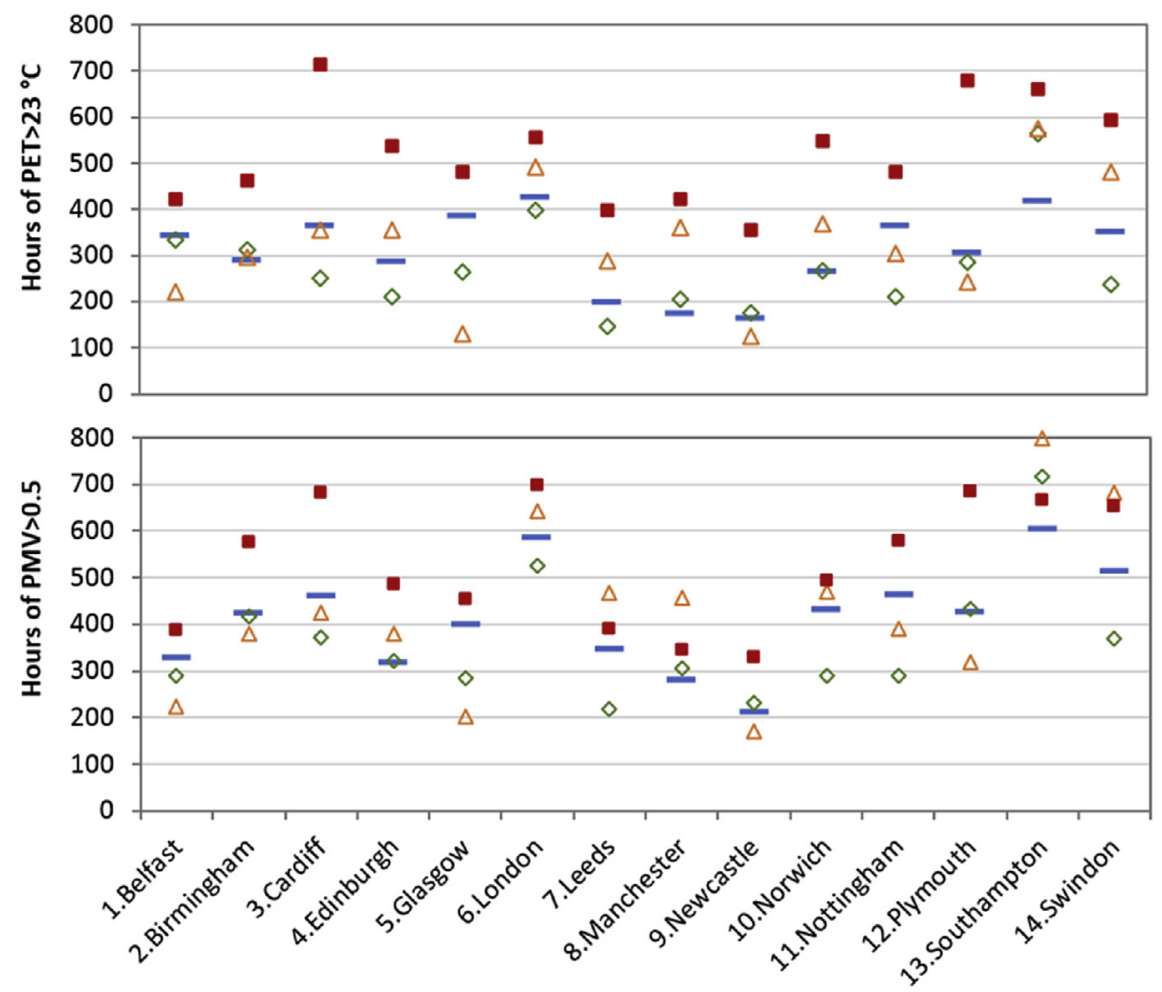

- 90th TRY $\diamond$ 90th DSY $\triangle$ 90th HSY-1 - 90th HSY-2

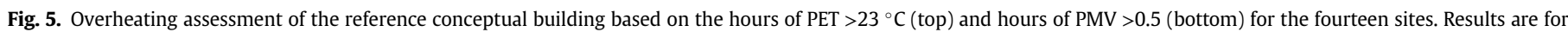
the $90^{\text {th }}$ percentile TRY, DSY, HSY-1 and HSY-2. 
Table 3

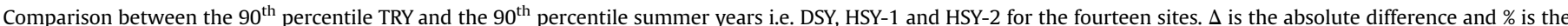

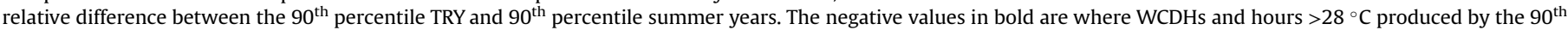
percentile summer years are less than the $90^{\text {th }}$ percentile TRY. $\mathrm{N}$ is the number of occurrences.

\begin{tabular}{|c|c|c|c|c|c|c|c|c|}
\hline \multirow[t]{2}{*}{ UK sites } & \multicolumn{4}{|l|}{ WCDH } & \multicolumn{4}{|c|}{ Hours $>28{ }^{\circ} \mathrm{C}$} \\
\hline & $90^{\text {th }}$ TRY & $\begin{array}{l}90^{\text {th }} \text { DSY } \\
\Delta(\%)\end{array}$ & $\begin{array}{l}90^{\text {th }} \text { HSY-1 } \\
\Delta(\%)\end{array}$ & $\begin{array}{l}90^{\text {th }} \text { HSY-2 } \\
\Delta(\%)\end{array}$ & $90^{\text {th }}$ TRY & $\begin{array}{l}90^{\text {th }} \text { DSY } \\
\Delta(\%)\end{array}$ & $\begin{array}{l}90^{\text {th }} \text { HSY-1 } \\
\Delta(\%)\end{array}$ & $\begin{array}{l}90^{\text {th }} \text { HSY-2 } \\
\Delta(\%)\end{array}$ \\
\hline 1 Belfast & 311 & $-238(-77)$ & 1075 (345) & $252(81)$ & 12 & $-12(-100)$ & $30(250)$ & $11(92)$ \\
\hline 2 Birmingham & 3312 & $270(8)$ & $3250(98)$ & 4588 (139) & 154 & $25(16)$ & $39(25)$ & $149(97)$ \\
\hline 3 Cardiff & 1336 & $-50(-4)$ & 2359 (177) & $-699(-52)$ & 75 & $28(37)$ & $86(115)$ & $-49(-65)$ \\
\hline 4 Edinburgh & 790 & $266(34)$ & $924(117)$ & $-659(-83)$ & 31 & $40(129)$ & 37 (119) & $-31(-100)$ \\
\hline 5 Glasgow & 721 & $-57(-8)$ & $1166(162)$ & $-97(-13)$ & 40 & $6(15)$ & $41(103)$ & $-6(-15)$ \\
\hline 6 London & 3491 & $1232(35)$ & $6272(180)$ & $3011(86)$ & 244 & $-17(-7)$ & $98(40)$ & $101(41)$ \\
\hline 7 Leeds & 1953 & $-958(-49)$ & 3069 (157) & $-837(-43)$ & 107 & $-46(-43)$ & $79(74)$ & $-76(-71)$ \\
\hline 8 Manchester & 1547 & $-113(-7)$ & 2469 (160) & $-1281(-83)$ & 77 & $43(56)$ & 93 (121) & $-69(-90)$ \\
\hline 9 Newcastle & 181 & 197 (109) & 1293 (715) & $-3(-2)$ & 9 & $2(22)$ & $49(544)$ & $-1(-11)$ \\
\hline 10 Norwich & 2222 & $-1343(-60)$ & 2105 (95) & $-809(-36)$ & 107 & $-70(-65)$ & $111(104)$ & $-48(-45)$ \\
\hline 11 Nottingham & 3892 & $-2522(-65)$ & $1588(41)$ & $3351(86)$ & 194 & $-119(-61)$ & $-43(-22)$ & $163(84)$ \\
\hline 12 Plymouth & 1282 & $1429(111)$ & $1667(130)$ & $-275(-21)$ & 82 & $122(149)$ & $62(76)$ & $-21(-26)$ \\
\hline 13 Southampton & 4824 & $7290(151)$ & 6457 (134) & $-1908(-40)$ & 256 & $244(95)$ & $208(81)$ & $-76(-30)$ \\
\hline 14 Swindon & 4665 & $-2347(-50)$ & $4203(90)$ & $2025(43)$ & 260 & $-101(-39)$ & $145(56)$ & $14(5)$ \\
\hline $\mathrm{N} / 14$ & - & $8 / 14$ & $0 / 14$ & $9 / 14$ & - & $6 / 14$ & $1 / 14$ & $9 / 14$ \\
\hline
\end{tabular}

Table 4

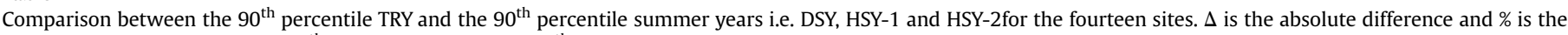

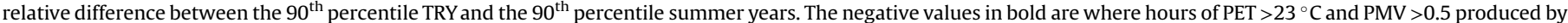
the $90^{\text {th }}$ percentile summer years are less than the $90^{\text {th }}$ percentile TRY. $\mathrm{N}$ is the number of occurrences.

\begin{tabular}{|c|c|c|c|c|c|c|c|c|}
\hline \multirow[t]{2}{*}{ UK sites } & \multicolumn{4}{|c|}{ Hours of PET above $23^{\circ} \mathrm{C}$} & \multicolumn{4}{|c|}{ Hours of PMV above 0.5} \\
\hline & $90^{\text {th }}$ TRY & $\begin{array}{l}90^{\text {th }} \text { DSY } \\
\Delta(\%)\end{array}$ & $\begin{array}{l}90^{\text {th }} \text { HSY-1 } \\
\Delta(\%)\end{array}$ & $\begin{array}{l}90^{\text {th }} \text { HSY-2 } \\
\Delta(\%)\end{array}$ & $90^{\text {th }} \mathrm{TRY}$ & $\begin{array}{l}90^{\text {th }} \text { DSY } \\
\Delta(\%)\end{array}$ & $\begin{array}{l}90^{\text {th }} \text { HSY-1 } \\
\Delta(\%)\end{array}$ & $\begin{array}{l}90^{\text {th }} \text { HSY-2 } \\
\Delta(\%)\end{array}$ \\
\hline 1 Belfast & 345 & $-11(-3)$ & $-125(-36)$ & $76(22)$ & 12 & $-39(-12)$ & $-106(-32)$ & $60(18)$ \\
\hline 2 Birmingham & 288 & $27(9)$ & $9(3)$ & $174(60)$ & 154 & $-5(-1)$ & $-42(-10)$ & $153(36)$ \\
\hline 3 Cardiff & 362 & $-109(-30)$ & $-7(-2)$ & $352(97)$ & 75 & $-90(-20)$ & $-36(-8)$ & $222(48)$ \\
\hline 4 Edinburgh & 286 & $-75(-26)$ & $68(24)$ & $252(88)$ & 31 & $4(1)$ & $62(20)$ & $169(53)$ \\
\hline 5 Glasgow & 386 & $-122(-32)$ & $-257(-67)$ & $95(25)$ & 40 & $-115(-29)$ & $-197(-49)$ & $56(14)$ \\
\hline 6 London & 425 & $-27(-6)$ & $69(16)$ & $131(31)$ & 244 & $-61(-10)$ & $58(10)$ & $112(19)$ \\
\hline 7 Leeds & 195 & $-46(-24)$ & $93(48)$ & $203(104)$ & 107 & $-131(-38)$ & $119(34)$ & $42(12)$ \\
\hline 8 Manchester & 172 & $35(20)$ & 187 (109) & $250(145)$ & 77 & $27(10)$ & $177(63)$ & $65(23)$ \\
\hline 9 Newcastle & 165 & $12(7)$ & $-38(-23)$ & 189 (115) & 9 & $19(9)$ & $-42(-20)$ & $117(55)$ \\
\hline 10 Norwich & 264 & $2(1)$ & $105(40)$ & $282(107)$ & 107 & $-143(-33)$ & $38(9)$ & $63(15)$ \\
\hline 11 Nottingham & 364 & $-153(-42)$ & $-59(-16)$ & $117(32)$ & 194 & $-174(-38)$ & $-72(-16)$ & $117(25)$ \\
\hline 12 Plymouth & 306 & $-22(-7)$ & $-65(-21)$ & $374(122)$ & 82 & $7(2)$ & $-108(-25)$ & $258(60)$ \\
\hline 13 Southampton & 416 & $146(35)$ & $161(39)$ & $245(59)$ & 256 & $113(19)$ & $194(32)$ & $60(10)$ \\
\hline 14 Swindon & 352 & $-113(-32)$ & $127(36)$ & $240(68)$ & 260 & $-145(-28)$ & $170(33)$ & $141(27)$ \\
\hline $\mathrm{N} / 14$ & - & $9 / 14$ & $6 / 14$ & $0 / 14$ & - & $9 / 14$ & $7 / 14$ & $0 / 14$ \\
\hline
\end{tabular}

of the UKCP09 weather generator. In Fig. 10 and Fig. 11, pTRY, pHSY1 and pHSY-2 in group (a) were created based on the weather data from an initial run of UKCP09 weather generator, whereas group (b) are from a second run of the weather generator. The four assessment metrics were used to examine both groups of weather files.

Fig. 10 presents overheating risk from the 10th, 50th and 90th percentile TRY, HSY-1 and HSY-2 in both groups using assessment metric (1) and (2). WCDH and hours $>28{ }^{\circ} \mathrm{C}$ calculated from the 10 th percentile HSY-2 in group (a) are substantially greater whereas in group (b) are fewer than the 10th percentile TRY. However, WCDH and hours $>28{ }^{\circ} \mathrm{C}$ calculated from the 10th, 50th and 90th percentile HSY-1 in both groups are constantly greater than these from pTRY. Furthermore, the absolute differences of pHSY-1 between group (a) and group (b) are small compared with those of pHSY-2.

Fig. 11 reveals discomfort hours from the 10th, 50th and 90th percentile TRY, HSY-1 and HSY-2 in both groups using assessment metric (3) and (4). The differences of hours of PET $>23^{\circ} \mathrm{C}$ and PMV $>0.5$ between group (a) and (b) are $-10 \%$ and $-13 \%$ for 10 th percentile HSY-2, $-4 \%$ and $-4 \%$ for the 50 th percentile HSY-2, $-4 \%$ and $-8 \%$ for 90 th percentile HSY- 2 respectively. It indicates that the differences from iterations of UKCP09 weather generator have little impact on the low to high percentile HSY-2 when using assessment metric (3) and (4). It can also be seen that hours of PET $>23^{\circ} \mathrm{C}$ and PMV $>0.5$ produced by the pHSY- 2 in both groups are always greater than the pTRY. The pHSY-1 in group (a) and (b), however, fail to produce more discomfort hours than the pTRY. For instance, the 10th percentile HSY-1 in group (a) shows greater but in group (b) fewer hours of PET $>23{ }^{\circ} \mathrm{C}$ than the 10th percentile TRY; the 90th percentile HSY-1 in group (a) shows fewer but in group (b) more hours of PMV $>0.5$ than the 90th percentile TRY. The relative differences of the 90th percentile HSY-1 between the two groups are $60 \%$ and $43 \%$ which are significantly high compared with 90 th percentile HSY-2.

In short, WCDH and hours $>28^{\circ} \mathrm{C}$ given by the pHSY- 1 as well as hours of PET $>23{ }^{\circ} \mathrm{C}$ and PMV $>0.5$ given by pHSY-2 are not influenced by the random sampling method of UKCP09 weather generator.

\subsection{Engineering choices}

As the method outlined can produce probabilistic weather files, 

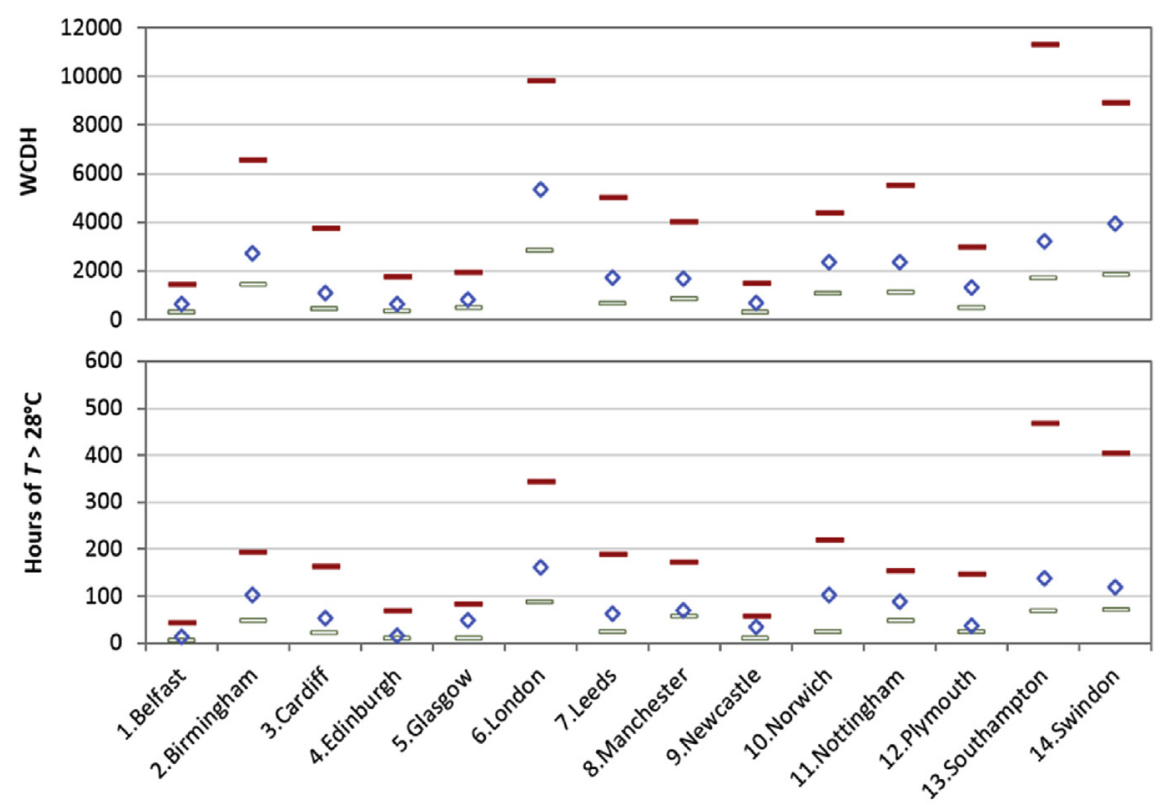

- 10th HSY-1 $\diamond$ 50th HSY-1 - 90th HSY-1

Fig. 6. Summer overheating hours from the 10th, 50 th, and 90 th percentile HSY-1. Top is Weighted Cooling Degree Hours; bottom is hours of external temperature $>28{ }^{\circ} \mathrm{C}$.
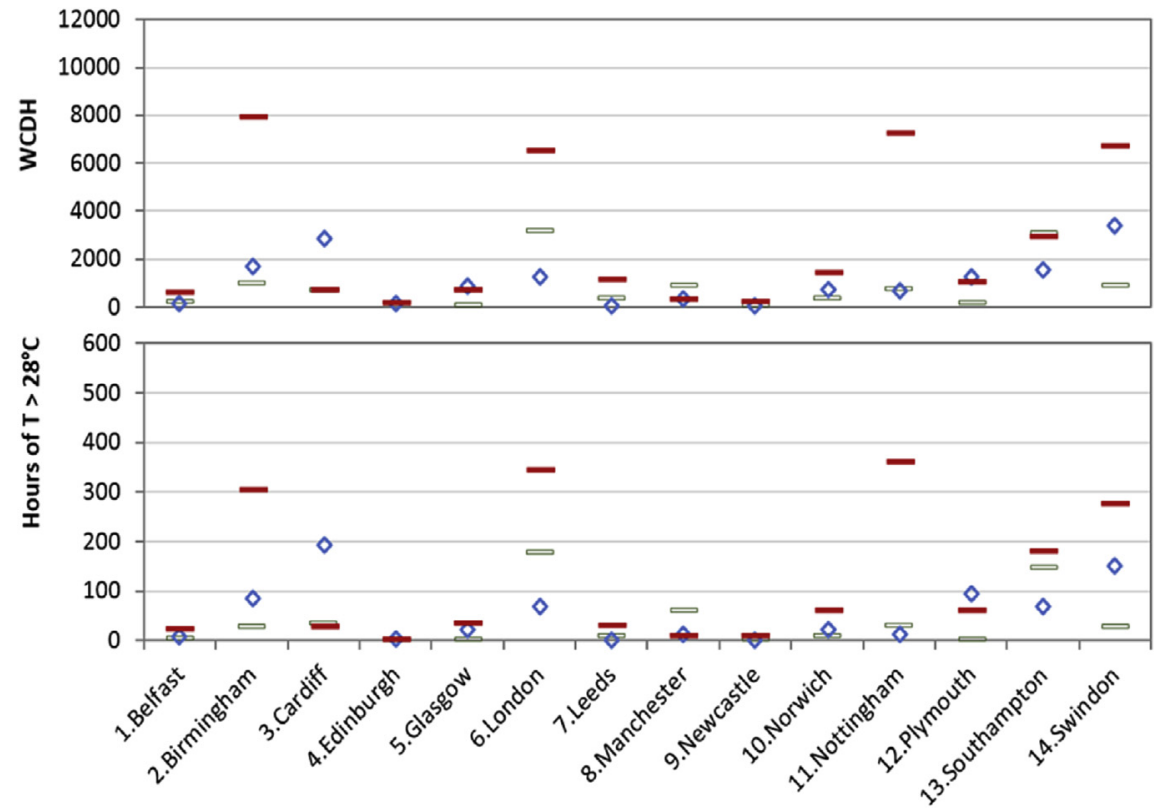

- 10th HSY-2 $\diamond 50$ th HSY-2 - 90th HSY-2

Fig. 7. Summer overheating hours from the 10th, 50th, and 90th percentile HSY-2. Top is Weighted Cooling Degree Hours; bottom is hours of external temperature $>28{ }^{\circ} \mathrm{C}$.

the engineer needs to select which percentile to model with. There is an argument against providing probabilistic future weather files since building designers might prefer the simplicity of using a single file. However, there are uncertainties in the climate models, so this would be possibly ill advised, and hence the use of probabilistic future weather years is more robust. As suggested earlier, this will in part depend on the building and the client. The 90th percentile HSY-1/2 represents a situation that is only predicted to be exceeded by approximately $10 \%$ of current predictions of future climate. The 50th percentile HSY-1/2 can be seen as representing the median predictions of climate models with respect to extremes, and the 10th percentile as a situation exceeded by all but $10 \%$ of predictions of the extremes. In Section 4.2 it was shown that the percentiles follow a logical order. Fig. 12 shows the situation in more detail. Here WCDH and hours $>28{ }^{\circ} \mathrm{C}$ are shown for pHSY-1, and hours of PET $>23{ }^{\circ} \mathrm{C}$ and PMV $>0.5$ for pHSY-2, with $\mathrm{p}$ ranging from 10th to 90th in ten steps. Linear regression between hours $>28{ }^{\circ} \mathrm{C}$ and WCDH for pHSY- 1 gives an $\mathrm{R}^{2}$ of 0.90 ; while between hours of PMV $>0.5$ and PET $>23{ }^{\circ} \mathrm{C}$ gives an $\mathrm{R}^{2}$ of 0.84 . So, as one might expect, the metrics are highly correlated. Looking at 

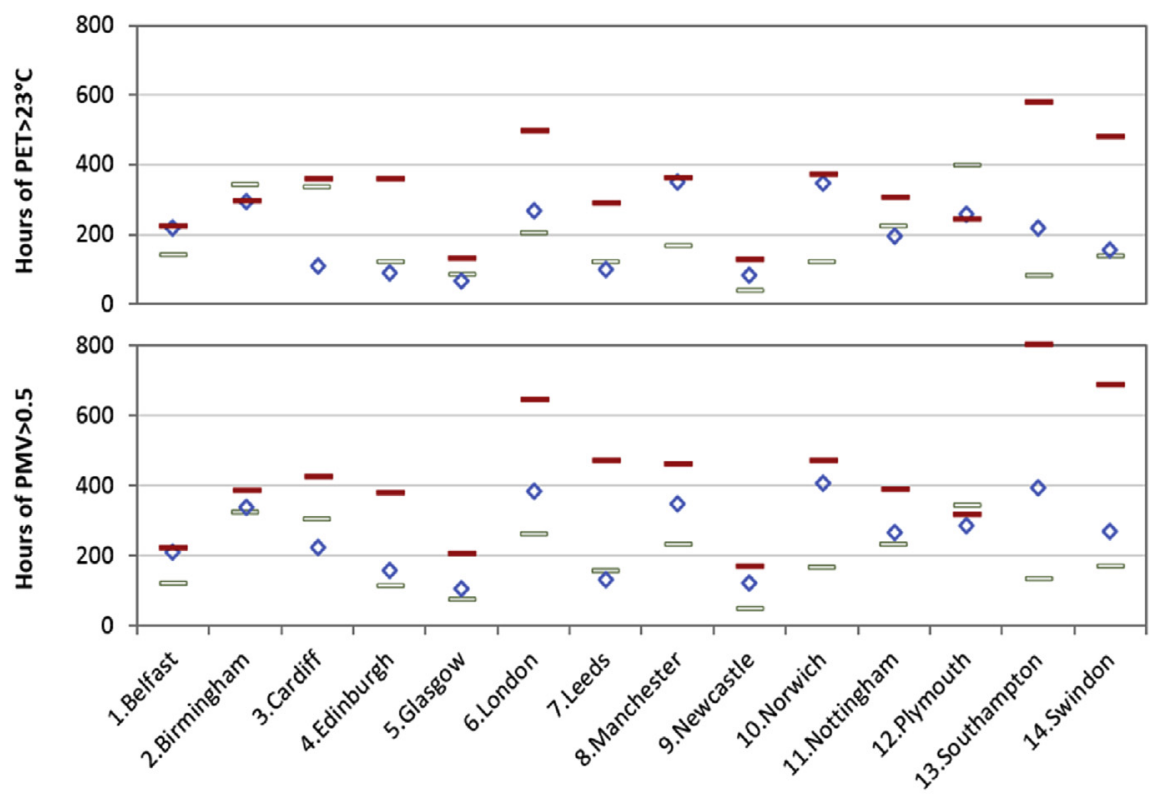

- 10th HSY-1 $\quad$ 50th HSY-1 - 90th HSY-1

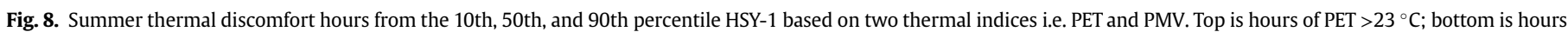
of PMV $>0.5$.
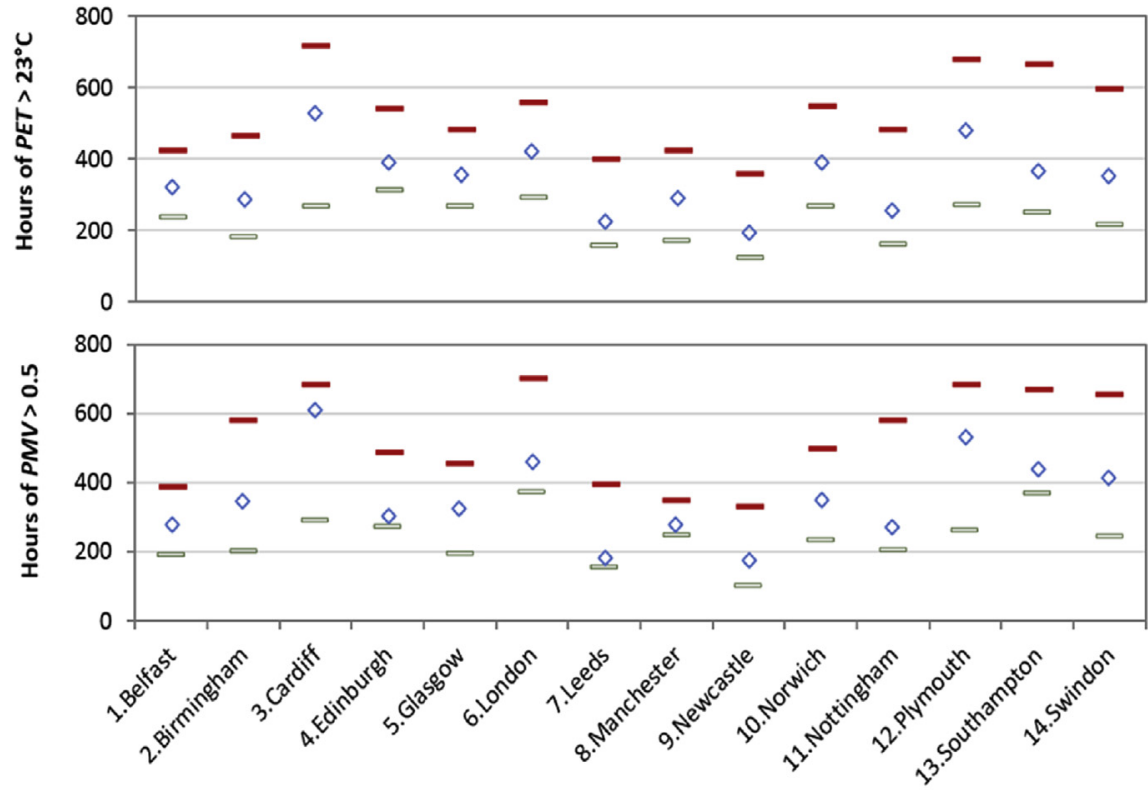

-10 th HSY-2 $\diamond 50$ th HSY-2 $\quad$ - 90th HSY-2

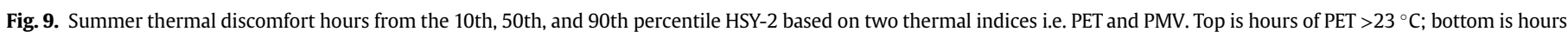
of PMV $>0.5$.

how all four metrics change with percentile, we have Table 5 . Although the correlation coefficients are all substantial, and for WCDH and hours of PET $>23^{\circ} \mathrm{C}$, in all cases an increase in percentile gives an increase in value (i.e. both are monotonically increasing functions), for hours over $28^{\circ} \mathrm{C}$ and PMV this monotonic behaviour cannot be guaranteed. However it is true at the larger scale. It would therefore seem sensible to recommend that in engineering studies a maximum of a low, medium and high percentile are used (probably 10th, 50th and 90th percentiles).
In any practical application whether pHSY1 or pHSY2 is used will depend on the way overheating is to be assessed. If a simple traditional metric (such as hours above a set temperature) is to be used then pHSY1 would be more appropriate. If however a more complex metric (such as PMV) is to be used pHSY2 would be more sensible and robust. 


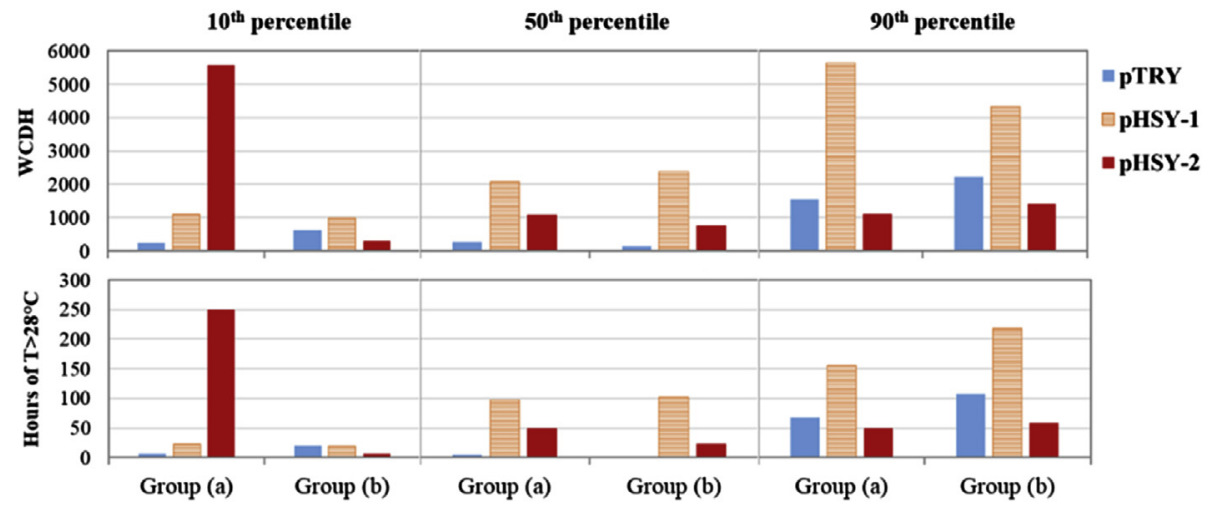

Fig. 10. Summer overheating hours in Norwich caused by the 10th, 50th and 90th percentile TRY, HSY-1 and HSY-2 in group (a) and in group (b).

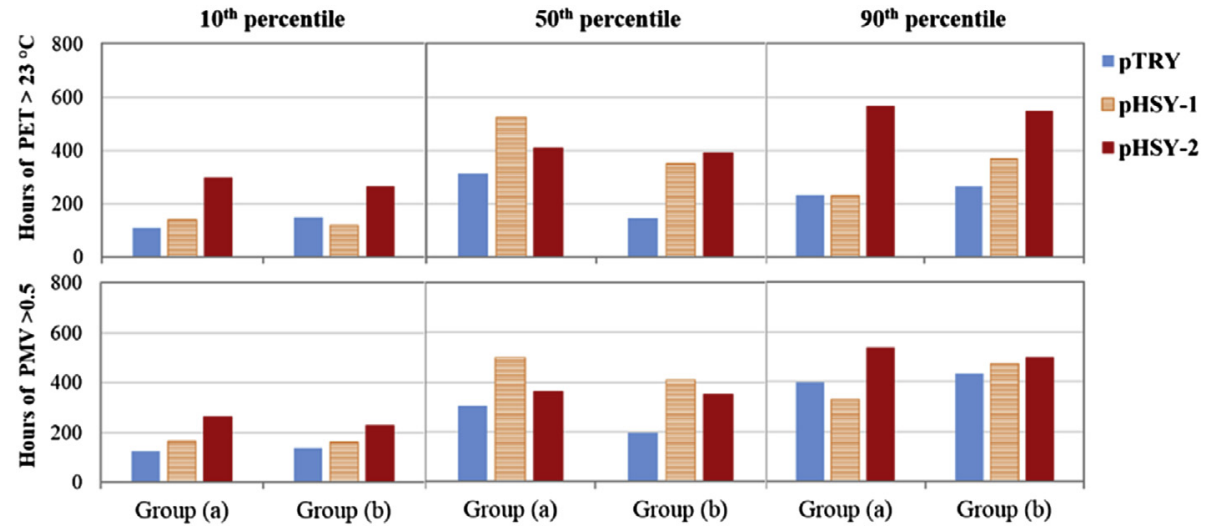

Fig. 11. Summer thermal discomfort hours in Norwich caused by the 10th, 50th and 90th percentile TRY, HSY-1 and HSY-2 in group (a) and in group (b).

\section{Conclusions}

This study proposes two new approaches for the creation of future summer reference years to assess overheating risk and thermal discomfort under a changing climate. The future pHSY-1 was created based on the ascending order of WCDH while future pHSY-2 was created based on ascending order of hours of PET $>23{ }^{\circ} \mathrm{C}$. The use of WCDH for pHSY-1 highlights weather years with periods of high temperatures, which have the potential to cause significant overheating in buildings, as measured using traditional simple metric. The pHSY-2 is based upon the PET, which highlights weather years which will have a significant impact upon human thermal comfort. It should be noted that both pHSY-1 and pHSY-2 represent the hot, but not extreme (i.e. heat wave), summer years. In consistent to the usage of CIBSE DSY, the pHSY-1 and pHSY2 are used for assessing the risk of overheating and discomfort hours during all summer (April to September) rather than an extreme hot event such as heatwave. It is as yet unknown how to accurately create future heatwaves which cause death. According to the Environmental Health Perspectives and the National Institute of Environmental Health Sciences [9], however, the increased average temperature also has a great influence on the heat-related illness. Thus, pHSY-1 and pHSY- 2 might not be suitable for indicating heatrelated death directly but indicating potential morbidity and mortality. They have been compared to the existing future pTRY and pDSY for fourteen sites around the UK using a conceptual reference building and four different assessment metrics. The results from the investigations could be summarised as follows.
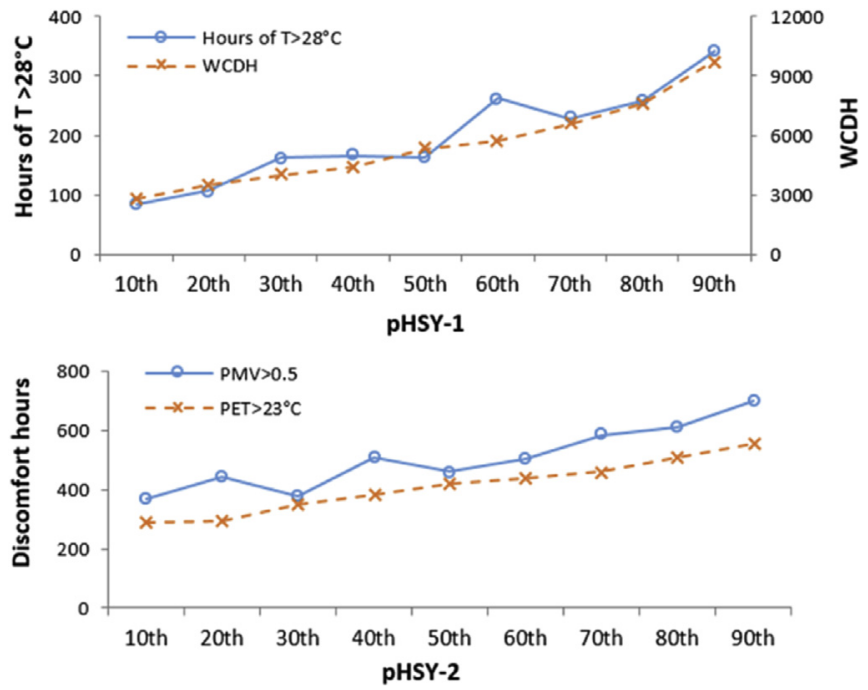

Fig. 12. Overheating hours and discomfort hours with increasing percentile HSY-1 and HSY-2 for London.

Table 5

$\mathrm{R}^{2}$ with respect to percentile for the four metrics.

\begin{tabular}{lllll}
\hline & WCDH & hours $>28{ }^{\circ} \mathrm{C}$ & Hours of PET $>23{ }^{\circ} \mathrm{C}$ & Hours of PMV $>0.5$ \\
\hline $\mathrm{R}^{2}$ & 0.94 & 0.90 & 0.99 & 0.87 \\
\hline
\end{tabular}


- We find that the pHSY-1 consistently indicates greater WCDH and hours $>28{ }^{\circ} \mathrm{C}$ than the equivalent pTRY and the pHSY-2 consistently indicates more hours of PET $>23{ }^{\circ} \mathrm{C}$ and PMV $>0.5$ than the pTRY for all fourteen UK sites. Furthermore we find that the pDSY does not consistently show more overheating or thermal discomfort than the pTRY, likely due to the simple selection methodology.

- WCDH and hours $>28^{\circ} \mathrm{C}$ increase with increasing percentiles for the pHSY-1. Similarly, higher percentiles of HSY-2 consistently produce more hours of PET $>23{ }^{\circ} \mathrm{C}$ and PMV $>0.5$. We find a linear relationship $\left(R^{2}=0.92\right)$ between WCDH and hours $>28^{\circ} \mathrm{C}$ for the pHSY-1. It has been shown that PET $>23^{\circ} \mathrm{C}$ is comparable to PMV >0.5 (Matzarakis and Mayer, 1996); here, we found a close linear relationship $\left(\mathrm{R}^{2}=0.88\right)$ between the hours of PET $>23{ }^{\circ} \mathrm{C}$ and hours of PMV $>0.5$ for pHSY- 2 .

- According to the comparison between group (a) and group (b), any variation due to the random sampling method used by the UKCP09 weather generator has little impact on WCDH and hours $>28{ }^{\circ} \mathrm{C}$ given by pHSY-1. Similarly, its influence on hours of PET $>23{ }^{\circ} \mathrm{C}$ and PMV $>0.5$ calculated from pHSY-2 are negligibly small.

- The results presented in this paper highlight an important limitation of using different metrics to compare overheating years. If the weather year is created based upon ranking of a single environmental variable such as temperature then assessment should be with similar metrics (e.g. hours $>28^{\circ} \mathrm{C}$ or $\mathrm{WCDH}$ ), if the weather year is based upon several environmental variables then a composite metric is required (e.g. PMV or PET). Using inappropriate metrics produces inconsistent results. This has important implications for the suitability of different weather files for either overheating or thermal comfort analysis.

From the above discussion, pHSY-1 could be used for determining the occurrence of overheating based on a benchmark peak summer temperature (e.g. $28^{\circ} \mathrm{C}$ as recommended in CIBSE Guide A [39]). It would also be appropriate to use pHSY-1 for assessing the severity of overheating based on the WCDH, which has greater emphasis on the higher summer temperature. Thermal comfort however, relies on several weather parameters including temperature, air movement and humidity. The pHSY-2 could therefore be used to assess the thermal discomfort or heat stress based on a thermal index such as PET or PMV. These thermal indices can indicate the level of heat stress (Matzarakis and Mayer, 1996) which is of importance to human health and well-being. CIBSE Guide A [39] simply recommends that hours of operative temperature above $28^{\circ} \mathrm{C}$ should not exceed $1 \%$ of annual occupied hours in living room. However, there are so far no criteria based upon the thermal index that defines whether a building is thermally acceptable or not. It is therefore suggested research on an alternative thermal comfort standard based on thermal index (e.g. a limit for the number or fraction of occupied hours with PMV $>0.5$ ) is required.

\section{Future work}

Two natural extensions to the work are the inclusion of the urban heat island (UHI) effect and the production of pHSY-1 and 2 for other locations with very different climates. Unfortunately, the UKCP09 weather generator cannot account for the UHI so other methods will have to be used. In order to create pHSY-1 and pHSY-2 worldwide suitable future weather data is required. In order to do this probabilistic climate change projections for other countries can be obtained from projections from regional and global climate models and morphing [17] applied. Both these extensions will hopefully be addressed in future work.

\section{Acknowledgement}

We are grateful to Jiantao Du and Sukumar Natarajan for their support on this article. We also would like to thank Andreas Matzarakis who provided RanMan Pro software which is used for calculating Physiologically Equivalent Temperature. This research was supported by Engineering and Physical Science Research Council (EPSRC) via grants EP/M021890/1. All data created during this research are available from the University of Bath data archive at http://doi.org/10.15125/BATH-00190.

\section{References}

[1] IPCC, Climate change 2013: the physical science basis, in: Contribution of Working Group I to the Fifth Assessment Report of the Intergovernmental Panel on Climate Change. Cambridge, United Kingdom and New York, Cambridge University Press, NY, USA, 2013.

[2] UNFCCC, Adoption of the Paris agreement-Proposal by the President-Draft decision -/CP.21. 2015, in: Paris Climate Conference. Paris, 2015.

[3] C. Demanuele, A. Mavrogianni, M. Davies, M. Kolokotroni, I. Rajapaksha, Using localised weather files to assess overheating in naturally ventilated offices within London's urban heat island, Build. Serv. Eng. Res. Technol. 33 (2012) 351-369.

[4] R. Gupta, M. Gregg, Using UK climate change projections to adapt existing English homes for a warming climate, Build. Environ. 55 (2012) 20-42.

[5] M.F. Jentsch, A.S. Bahaj, P.A.B. James, Climate change future proofing of buildings-Generation and assessment of building simulation weather files, Energy Build. 40 (2008) 2148-2168.

[6] R.S. McLeod, C.J. Hopfe, A. Kwan, An investigation into future performance and overheating risks in Passivhaus dwellings, Build. Environ. 70 (2013) 189-209.

[7] S. Patidar, D.P. Jenkins, G.J. Gibson, P.F.G. Banfill, Statistical techniques to emulate dynamic building simulations for overheating analyses in future probabilistic climates, J. Build. Perform. Simul. 4 (2011) 271-284.

[8] J. Taylor, M. Davies, A. Mavrogianni, Z. Chalabi, P. Biddulph, E. Oikonomou, et al., The relative importance of input weather data for indoor overheating risk assessment in dwellings, Build. Environ. 76 (2014) 81-91.

[9] A Human Health Perspective On Climate Change - A Report Outlining the Research Needs on the Human Health Effects of Climate Change. Environmental Health Perspectives and the National Institute of Environmental Health Sciences.

[10] S. Vandentorren, P. Bretin, A. Zeghnoun, L. Mandereau-Bruno, A. Croisier, C. Cochet, et al., August 2003 heat wave in France: risk factors for death of elderly people living at home, Eur. J. public health 16 (2006) 583-591.

[11] G.J. Levermore, J.B. Parkinson, Analyses and algorithms for new test reference years and design summer years for the UK, Build. Serv. Eng. Res. Technol. 27 (2006) 311-325

[12] M.F. Jentsch, G.J. Levermore, J.B. Parkinson, M.E. Eames, Limitations of the CIBSE design summer year approach for delivering representative nearextreme summer weather conditions, Build. Serv. Eng. Res. Technol. 35 (2013) 155-169.

[13] M.F. Jentsch, M.E. Eames, G.J. Levermore, Generating near-extreme Summer Reference Years for building performance simulation, Build. Serv. Eng. Res. Technol. 36 (2015) 701-727.

[14] CIBSE, CIBSE TM33: Tests for Software Accreditation and Verification, Chartered Institution of Building Services Engineers, London, 2006.

[15] M. Eames, An update of the UK's design summer years: probabilistic design summer years for enhanced overheating risk analysis in building design, Build. Serv. Eng. Res. Technol. (2016) 1-20, http://dx.doi.org/10.1177/ 0143624416631131. Published online before print February 29, 2016.

[16] S. Coles, An Introduction to Statistical Modelling of Extreme Values, Springer Science and Business Media, London, 2013.

[17] David Ferrari, T. Lee, Beyond TMY: climate data for specific application, in: Proceedings 3rd International Solar Energy Society Conference - Asia Pacific Region (ISES-AP-08), 2008. Sydney, Australia.

[18] T. Frank, Climate change impacts on building heating and cooling energy demand in Switzerland, Energy Build. 37 (2005) 1175-1185.

[19] S.E. Belcher, J.N. Hacker, D.S. Powell, Constructing design weather data for future climates, Build. Serv. Eng. Res. Technol. 26 (2005) 49-61.

[20] M.F. Jentsch, Climate Change Weather File Generator (CCWeatherGen), Sustainable Energy Research Group, University of Southampton, 2012.

[21] P.D. Jones, C.G. Kilsby, C. Harpham, V. Glenis, A. Burton, UK Climate Projections Science Report: Projections of Future Daily Climate for the UK from the Weather Generator, University of Newcastle, UK University of Newcastle, UK, 2010.

[22] S.T, Smith, V. Hanby, Methodologies for the generation of design summer years for building energy simulation using UKCP09 probabilistic climate projections, Build. Serv. Eng. Res. Technol. 33 (2012) 9-17.

[23] M. Eames, T. Kershaw, D. Coley, On the creation of future probabilistic design weather years from UKCP09, Build. Serv. Eng. Res. Technol. 32 (2010) $127-142$.

[24] R. Watkins, G. Levermore, J. Parkinson, The design reference year - a new 
approach to testing a building in more extreme weather using UKCP09 projections, Build. Serv. Eng. Res. Technol. 34 (2012) 165-176.

[25] T. Kershaw, M. Eames, D. Coley, Comparison of multi-year and reference year building simulations, Build. Serv. Eng. Res. Technol. 31 (2010) 357-369.

[26] IPCC, Emission Scenarios. The Edinburgh Building Shaftesbury Road, Cambridge CB2 2RU ENGLAND, Cambridge Universtiy Press, 2000.

[27] R. Watkins, G. Levermore, J. Parkinson, Constructing a future weather file for use in building simulation using UKCP09 projections, Build. Serv. Eng. Res. Technol. 32 (2011) 293-299.

[28] CIBSE, CIBSE TM 49: Design Summer Years for London, The Chatered Institution of Building Services Engineers, London, 2014.

[29] J.F. Nicol, J. Hacker, B. Spires, H. Davies, Suggestion for new approach to overheating diagnostics, Build. Res. Inf. 37 (2009) 348-357.

[30] A. Matzarakis, H. Mayer, Another Kind of Environmental Stress: Thermal Stress, WHO - Collaborating centre for air quality management and air pollution control, Dessau-Roßlau, 1996.

[31] BSI, BS EN 15251:2007: Indoor Environmental Input Paramerters for Design and Assessment of Energy Performance of Buildings Addressing Indoor Air Quality, Thermal Environment, Lighting and Acoustics, British Standards Institution, London, 2007.

[32] H. Mayer, P. Höppe, Thermal comfort of man in different urban environments,
Theor. Appl. Climatol. 38 (1987) 43-49.

[33] VDI, Methods for the Human-biometeorological Assessment of Climate and Air Hygiene for Urban and Regional Planning, in: Part I: Climate. VDI Guideline 3787. Part 2, Beuth, Berlin, 1998.

[34] P. Höppe, Die Energiebilanz des menschen, Universitat Munchen, Meteorologisches Institut, Munich, 1984.

35] P. Höppe, Heat balance modelling, Experientia 49 (1993) 741-746.

[36] A. Matzarakis, F. Rutz, H. Mayer, Modelling radiation fluxes in simple and complex environments-application of the RayMan model, Int. J. biometeorology 51 (2007) 323-334.

[37] T.-P. Lin, A. Matzarakis, R.-L. Hwang, Shading effect on long-term outdoor thermal comfort, Build. Environ. 45 (2010) 213-221.

[38] T.-P. Lin, A. Matzarakis, Tourism climate and thermal comfort in sun moon lake, Taiwan, Int. J. biometeorology 52 (2008) 281-290.

39] CIBSE, CIBSE Guide a: Environmental Design, The Chartered Institution of Building Services Engineers, London, 2006.

[40] ASHRAE, ANSI/ASHRAE Standard 55-2013 Thermal Environmental Conditions for Human Occupancy, 2013.

[41] P. Augspach, Assessing pedestrian thermal comfort within the Buenos Aires climatic context. 30th International PLEA Conference, CEPT University, Ahmedabad, 2014. 